\title{
Interspecific Hybrids Production between Lilium brownii var. colchesteri and Its Close Relatives by Ovary Slice Culture
}

\author{
Nguyen Thi Lam Hai ${ }^{1 *}$, Michikazu Hiramatsu², Jong-Hwa Kim³ ${ }^{3}$ Jun-ichiro Masuda² \\ and Hiroshi Okubo
}

\author{
${ }^{1}$ Graduate School of Bioresource and Bioenvironmental Sciences, Kyushu University, Fukuoka 812-8581, Japan \\ ${ }^{2}$ Faculty of Agriculture, Kyushu University, Fukuoka 812-8581, Japan \\ ${ }^{3}$ Department of Horticulture, Kangwon National University, Chuncheon 200-707, Korea
}

\begin{abstract}
Lilium brownii var. colchesteri (BRO) has a unique trait in its flower color. The color at anthesis is yellowish cream, and changes to white after one day. To introduce this trait and establish a sexually reproductive cultivation system for cut flower production in Lilium, interspecific crosses of $L$. $\times$ formolongi, $L$. formosanum, L. longiflorum (as seed parents) and BRO (as a pollen parent) were carried out. Capsules with unviable seeds were found in all crosses. To overcome the incongruity barrier, ovary slices excised from developing ovaries at 7 to 28 days after pollination (DAP) were cultured in Murashige and Skoog medium supplemented with $40 \mathrm{~g} \cdot \mathrm{L}^{-1}$ sucrose, $40 \mathrm{~g} \cdot \mathrm{L}^{-1}$ D-mannitol and $2.5 \mathrm{~g} \cdot \mathrm{L}^{-1}$ gellan gum under $24 \mathrm{~h}$ illumination. Hybrid plantlets were obtained from crosses of $L . \times$ formolongi $\times$ BRO and $L$.formosanum $\times$ BRO, but not from the cross of L.longiflorum $\times$ BRO. After acclimatization, $79(44.1 \%)$ of 179 hybrid plants produced flowers within a year of cultivation. The hybrids developed flowers changing from yellowish cream to white during anthesis as does the pollen parent. Twentyeight of 79 flowered plants sprouted two or more flower stalks, characteristics of $L$.formosanum. The hybrids exhibited relatively high pollen fertility and produced capsules, but no mature seed was obtained by selfpollination.
\end{abstract}

Key Words: interspecific cross, L. brownii var. colchesteri, L. $\times$ formolongi, L. formosanum, L. longiflorum.

\section{Introduction}

The genus Lilium spreads over the Northern Hemisphere and is centered mainly in Asia, North America, and Europe (Beattie and White, 1993), being composed of almost one hundred species (McRae, 1998). More than 7,000 cultivars have been bred until now (Leslie, 1982), mainly by intra- or inter-specific hybridization, and more than 100 new cultivars have been released annually over the past two decades.

Lilium brownii (F. E. Brown) Miellez var. colchesteri E. H. Wilson is endemic to nearly all parts of central China at elevations up to 1,500 meters (McRae, 1998). It seems to have been introduced and widely cultivated as an ornamental plant in Japan for about 400 years (Okubo, 2006). It has unique ornamental floral traits with graceful harmony in flower and anther color (brown color), elegant fragrance and petal color changing from yellowish cream to white during anthesis, which has not

Received; September 1, 2011. Accepted; November 25, 2011.

* Corresponding author (Email: lamhai1979@yahoo.com). been observed in other lilies. It was confirmed by molecular phylogenetic studies that the species is a close relative of $L$. formosanum and $L$. longiflorum (Nishikawa et al., 2001). To date, the lily has been grown naturally in house gardens in Korea or has been cultivated as a vegetable or as a component of traditional Chinese medicine in China (Okubo, 2006; Sashida et al., 1992). The species was, probably for the first time, used in breeding to establish Centifolium hybrids, later renamed Olympic hybrids, at Oregon Bulb Farms, USA by Jan de Graaff and his collaborators, who initiated their lily breeding program about 1940 (Benschop et al., 2010; Jefferson-Brown and Howland, 1995), although McRae (1998) said that the species was not used for hybridizing there. Interspecific crosses of L. brownii with L. longiflorum (Van Tuyl, 1980) and with L. formosanum (by Zalivski) were also reported by McRae (1998), but it does not seem that cultivars with the species-specific characters of L. brownii or var. colchesteri have ever been distributed. It is, however, difficult to cultivate the lily in our climate conditions, probably because it is susceptive to virus infection. 
Lilium formosanum, natively distributed in mainland Taiwan from sea level to 3,500 meters (Yang, 2000), reaches anthesis within 12 months after seed sowing (Hiramatsu et al., 2002) unlike other Lilium species that need several years to start flowering from seeds (Shimizu, 1971). The introduction of the earlyflowering ability of $L$. formosanum has been realized in only one cultivar group, $L . \times$ formolongi, a hybrid of L. formosanum and L. longiflorum (Beattie and White, 1993; Shimizu, 1971). The hybrid was used as parental materials to breed new lily cultivars with novel traits in flower color (Van Creij et al., 1993; Van Tuyl et al., 1986), multiple stalks, early flowering (Saruwatari et al., 2008), and fusarium resistance (Löffler et al., 1996). Style manipulations and embryo techniques were applied to conquer the pre- and post-fertilization barrier of interspecific crosses between these Longiflorum lilies with other species in the genus Lilium (Fukai and Tsuji, 2004; Kanoh et al., 1988; Van Creij et al., 1998; Van Tuyl et al., 1991). However, variation in floral characteristics among these species is very poor; the flowers show only white-colored petals, and funnel-shaped flowers with strong fragrance; therefore, introducing new floral traits into these species can enhance the variation of their flower color and enrich the lily world.

The purpose of this study was to demonstrate the possibility of interspecific breeding between L. brownii var. colchesteri and its close relatives including $L . \times$ formolongi, L. formosanum, and L. longiflorum, with the target of producing new lily cultivars endowed with the interesting floral traits of both parents, such as precocious flowering and petal color changing. To improve the hybridization process in lily, the authors attempted ovary slice culture at different periods after stigmatic pollination. The precocious flowering ability enables the expected new cultivars to grow from seeds, and this reproduction process can eliminate virus transmission. The hybridity of developed progenies was evaluated by isozyme analysis. Sexual reproductive ability and flower characteristics of $F_{1}$ hybrids were also investigated.

\section{Materials and Methods}

\section{Plant materials}

Lilium brownii var. colchesteri (BRO), collected in South Korea and vegetatively established from one clone, was used in all crosses as a paternal genotype. L. formosanum naturalized in Fukuoka Prefecture, Japan, L. $\times$ formolongi cvs. ' $F_{1}$ Augusta', ' $F_{1}$ Julia', 'Raizan 1', 'Sakigake Raizan', and 'White Lancer'; L. longiflorum 'Hinomoto' and seedlings established from the seeds of nine natural genotypes collected in the Ryukyu Archipelago and Taiwan (Table 1) were used as maternal genotypes. The plants were grown in the field and in an unheated greenhouse in Kyushu University, Fukuoka Prefecture, Japan.

\section{Pollination and ovary slice culture}

Normal pollination was carried out according to the method described by Van Tuyl et al. (1986). The ovaries at 7, 14, 18, 21, and 28 days after pollination (DAP) were surface-sterilized by immersion in $70 \%$ ethanol for $1 \mathrm{~min}$ followed by $2 \%$ sodium hypochlorite solution $(\mathrm{NaClO})$ with a few drops of surfactant (Tween 20) for $15 \mathrm{~min}$ and washed three times in sterilized distilled

Table 1. Capsule set in interspecific crosses using L. brownii var. colchesteri as the pollen parent.

\begin{tabular}{|c|c|c|c|c|}
\hline \multirow[b]{2}{*}{ Female parent } & \multirow{2}{*}{$\begin{array}{l}\text { Number of } \\
\text { crosses }\end{array}$} & \multicolumn{3}{|c|}{ Number of capsules } \\
\hline & & Aborted & $\begin{array}{c}\text { Without embryo } \\
(\%)\end{array}$ & With embryo \\
\hline \multicolumn{5}{|l|}{ L. $\times$ formolongi } \\
\hline ' $F_{1}$ Augusta' & 37 & 27 & $10(27.0)$ & 0 \\
\hline ' $F_{1}$ Julia' & 13 & 9 & $4(30.8)$ & 0 \\
\hline 'Raizan 1' & 13 & 8 & $5(38.5)$ & 0 \\
\hline 'Sakigake Raizan' & 27 & 21 & $6(22.2)$ & 0 \\
\hline 'White Lancer' & 28 & 21 & $7(25.0)$ & 0 \\
\hline L. formosanum & 51 & 51 & 0 & 0 \\
\hline \multicolumn{5}{|l|}{ L. longiflorum ${ }^{2}$} \\
\hline 'Hinomoto' & 41 & 41 & 0 & 0 \\
\hline LPI (Pitouchiao, Taiwan) & 40 & 32 & $8(20.0)$ & 0 \\
\hline LFU (Fulung, Taiwan) & 5 & 5 & 0 & 0 \\
\hline LYO (Yonaguni island, Ryukyu) & 25 & 25 & 0 & 0 \\
\hline LIS (Ishigaki island, Ryukyu) & 70 & 70 & 0 & 0 \\
\hline LMI (Miyako island, Ryukyu) & 9 & 9 & 0 & 0 \\
\hline LKU (Kume island, Ryukyu) & 64 & 64 & 0 & 0 \\
\hline LYR (Yoron island, Ryukyu) & 33 & 33 & 0 & 0 \\
\hline LOE (Okinoerabu island, Ryukyu) & 14 & 14 & 0 & 0 \\
\hline LKI (Kikai island, Ryukyu) & 46 & 46 & 0 & 0 \\
\hline
\end{tabular}

${ }^{z}$ Populations of L. longiflorum are arranged geographically. 
water. In vitro culture was carried out by the method described by Kanoh et al. (1988) and Saruwatari et al. (2008) with some modification. The swollen parts of the ovaries were cut into $2-3 \mathrm{~mm}$ thick slices; each sliced ovary disk with about 30 ovules was placed on culture medium in a test tube $(18 \times 180 \mathrm{~mm})$ and maintained at $25^{\circ} \mathrm{C}$ in the dark for four weeks before exposure to continuous illumination with fluorescent light. Ovule germination was recorded until ten months after culture.

A modified MS medium (Murashige and Skoog, 1962) containing $40 \mathrm{~g} \cdot \mathrm{L}^{-1}$ sucrose, $40 \mathrm{~g} \cdot \mathrm{L}^{-1}$ D-mannitol, and $2.5 \mathrm{~g} \cdot \mathrm{L}^{-1}$ gellan gum was used as the test medium. The medium was adjusted to $\mathrm{pH} 5.8$ and sterilized by autoclaving at $121^{\circ} \mathrm{C}$ and $1.1 \mathrm{~kg} \cdot \mathrm{cm}^{-2}$ for $15 \mathrm{~min}$.

Three weeks after germination, plantlets were transferred to test tubes $(18 \times 180 \mathrm{~mm})$ each containing $10 \mathrm{~mL}$ of half-strength MS medium supplemented with $20 \mathrm{~g} \cdot \mathrm{L}^{-1}$ sucrose and $2.5 \mathrm{~g} \cdot \mathrm{L}^{-1}$ gellan gum at $\mathrm{pH} 5.8$ and incubated at $25^{\circ} \mathrm{C}$ under illumination. The rooted plantlets with three leaves and approximately $3.5 \mathrm{~g}$ in weight were washed with tap water and transplanted to plastic pots $(9 \times 10 \mathrm{~cm}$, one bulblet per pot) containing vermiculite medium (Redi-earth, Sun Gro Hort. Canada Ltd., Canada). After six months of acclimatization at $20^{\circ} \mathrm{C}$ in a phytotron (Biotron Institute, Kyushu University) for optimal growth in winter, the seedlings were planted in spring in plastic pots $(15 \times 20 \mathrm{~cm})$ supplemented with commercial soil and grown in an unheated glasshouse where the temperature fluctuated from $5^{\circ} \mathrm{C}$ in winter to $43^{\circ} \mathrm{C}$ in summer. Liquid fertilizer (Hyponex, Hyponex Japan Co., Ltd., Japan) and pesticide were applied every two months. The number of flowering plants and flower stalks per plant, flower color, and anther color were recorded at the flowering stage twelve months after planting.

\section{Hybrid confirmation}

The produced plants were subjected to isozyme analysis to confirm their hybridity. The allozymes, diaphorase (DIA), aspartate aminotransferase (AAT), and glucosephophate isomerase (GPI) were analyzed according to the method of Hiramatsu et al. (2001). About $200 \mathrm{mg}$ young fresh leaves were homogenized in $200 \mu \mathrm{L}$ Tris- $\mathrm{HCl}$ grinding buffer. Crude extracts were soaked using paper wicks $(12 \times 3.5 \mathrm{~mm})$ and electrophoresed on horizontal starch gel (Nacalai Tesque Inc., Japan) at a constant voltage of $75 \mathrm{~V}$ for $6 \mathrm{~h}$; the isozymes were then evaluated by activity staining.

\section{Pollen fertility}

Flowers of hybrid progenies were emasculated one day before anthesis and self-pollination was performed one to three days later. The anther was harvested and dried for three days at $25^{\circ} \mathrm{C}$. Pollen stainability was determined by staining the fresh pollen in a drop of acetocarmine. In vitro germination of pollen was investigated by culturing the pollen grains on medium consisting of $10 \mathrm{~g} \cdot \mathrm{L}^{-1}$ sucrose, $0.1 \mathrm{~g} \cdot \mathrm{L}^{-1}$ boric acid, and $1.0 \mathrm{~g} \cdot \mathrm{L}^{-1}$ agar (Niimi and Shiokawa, 1992) at $25^{\circ} \mathrm{C}$ for $4 \mathrm{~h}$. At least 500 pollen grains were observed in each plant.

\section{Results}

A total of 524 interspecific pollinations were carried out in the flowering seasons of 2009 and 2010. Some cross combinations, such as with $L . \times$ formolongi ' $\mathrm{F}_{1}$ Augusta', 'F $F_{1}$ Julia', 'Raizan 1', 'Sakigake Raizan', and 'White Lancer' and with L. longiflorum 'LPI' (originated in Pitouchiao, mainland of Taiwan), produced capsules but they all failed to set mature seed (Table 1). Pollinated ovaries enlarged within one to six weeks after pollination; however, all the swollen capsules eventually withered and shrank before reaching the size of normal capsules.

Sliced ovary segments swelled and produced white swollen ovules after five weeks of culture (data not shown); however, most of the ovules gradually turned dark brown within ten weeks after incubation and failed to geminate, especially in the combinations of L. longiflorum $\times$ BRO (Table 2 ). The first ovule germination was recorded after eight weeks of culture in the cross combination of ' $F_{1}$ Augusta' $\times$ BRO at 28 DAP.

Germination of cultured ovules was observed in all cross combinations when L. $\times$ formolongi and L. formosanum were used as seed parents, and the germination rate varied from $0.1 \%$ to $11.2 \%$ depending upon maternal genotypes (Table 2). No germination occurred in the crosses using L. longiflorum as the seed parent. Cross combination of ' $\mathrm{F}_{1}$ Augusta' $\times \mathrm{BRO}$ at 28 DAP was recorded as the highest germination rate with $11.2 \%$ cultured ovules, and 241 bulblets were obtained. In the cross combinations of ' $\mathrm{F}_{1}$ Augusta' $\times \mathrm{BRO},{ }^{\prime} \mathrm{F}_{1}$ Julia' $\times$ BRO, 'Sakigake Raizan' $\times$ BRO, and 'White Lancer' $\times$ BRO the ovules cultured at 28 and 21 DAP had a higher germination rate than those cultured at earlier stages. In contrast, the initiation time of culture had a marked effect on the young ovules at early culturing stages compared to those at later stages in the cross combinations of 'Raizan 1' $\times$ BRO and L. formosanum $\times \mathrm{BRO}$, the highest germination rates were observed at 14 DAP and 7 DAP in the cross combinations of 'Raizan 1 ' $\times$ BRO and of L. formosanum $\times$ BRO, respectively.

Among three isozymes (AAT, DIA, GPI) tested, only diaphorase (DIA) generated clear zymograms. The DIA zymograms of the parents were distinctly different, and the hybrid plants had common bands for both parents (Fig. 1).

Seventy-nine of 179 acclimatized plantlets produced flowers within a year of cultivation, i.e. they reached anthesis in the second year from the date of pollination (Table 3 ). The hybrid progenies of five $L . \times$ formolongi cultivars and L.formosanum needed 660 to 695 days from pollination on average to yield the first flower. Twenty-eight of 79 flowered plants sprouted two or more flower stalks. A maximum of four flower stalks was observed only in the combination of ' $F_{1}$ Augusta' $\times$ BRO.

The hybrid plants produced larger flowers with a higher leaf index than the pollen parent (Table 5). The 
Table 2. Ovule germination from ovary-slice culture of interspecific crosses with L. brownii var. colchesteri (BRO) as the pollen parent.

\begin{tabular}{|c|c|c|c|c|}
\hline \multirow{2}{*}{ Female parent } & \multirow{2}{*}{$\begin{array}{l}\text { Days after } \\
\text { pollination }\end{array}$} & \multirow{2}{*}{$\begin{array}{l}\text { Number of } \\
\text { ovary disks }\end{array}$} & \multicolumn{2}{|c|}{ Number of ovules } \\
\hline & & & cultured $^{y}$ & germinated $(\%)^{\mathrm{z}}$ \\
\hline \multicolumn{5}{|l|}{ L. $\times$ formolongi } \\
\hline \multirow[t]{4}{*}{ ' $\mathrm{F}_{1}$ Augusta' } & 7 & 80 & 2400 & 0 \\
\hline & 14 & 7 & 210 & 0 \\
\hline & 21 & 132 & 3960 & $72 \quad(1.8)$ \\
\hline & 28 & 72 & 2160 & $241(11.2)$ \\
\hline \multirow[t]{4}{*}{ ' $\mathrm{F}_{1}$ Julia' } & 7 & 21 & 630 & 0 \\
\hline & 14 & 19 & 570 & 0 \\
\hline & 21 & 50 & 1500 & $4 \quad(0.3)$ \\
\hline & 28 & 19 & 570 & $12(2.1)$ \\
\hline \multirow[t]{2}{*}{ 'Raizan 1' } & 14 & 176 & 5280 & $50 \quad(0.9)$ \\
\hline & 28 & 42 & 1260 & $3(0.2)$ \\
\hline \multirow[t]{3}{*}{ 'Sakigake Raizan' } & 14 & 38 & 1140 & $30 \quad(2.6)$ \\
\hline & 21 & 9 & 270 & $8 \quad(3.0)$ \\
\hline & 28 & 18 & 540 & $24 \quad(4.4)$ \\
\hline \multirow[t]{2}{*}{ 'White Lancer' } & 18 & 60 & 1800 & $1 \quad(0.1)$ \\
\hline & 28 & 38 & 1140 & $10 \quad(0.9)$ \\
\hline \multirow[t]{3}{*}{ L. formosanum } & 7 & 43 & 1290 & $15 \quad(1.2)$ \\
\hline & 14 & 41 & 1230 & $7 \quad(0.6)$ \\
\hline & 21 & 43 & 1290 & $12(0.9)$ \\
\hline \multicolumn{5}{|l|}{ L. longiflorum } \\
\hline 'Hinomoto' & 20 & 30 & 900 & 0 \\
\hline LKI (Kikai island, Ryukyu) & 14 & 77 & 2310 & 0 \\
\hline \multirow[t]{3}{*}{ LPI (Pitouchiao, Taiwan) } & 7 & 40 & 1200 & 0 \\
\hline & 14 & 55 & 1650 & 0 \\
\hline & 21 & 50 & 1500 & 0 \\
\hline
\end{tabular}

${ }^{\mathrm{z}}$ Number of geminated ovules/Number of cultured ovules $\times 100$.

${ }^{y}$ Number of ovary disks $\times 30$ (Hayashi et al., 1986).

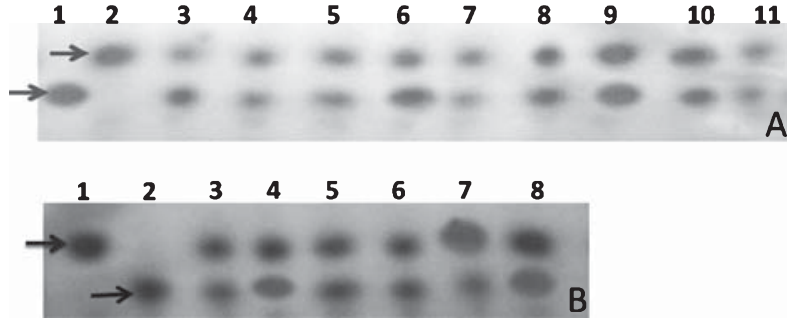

Fig. 1. Isozyme patterns for Diaphorase (DIA) in parental species and their hybrids. (A) Lane 1, L. $\times$ formolongi ' $\mathrm{F}_{1}$ Augusta'; Lane 2, L. brownii var. colchesteri (BRO); Lanes 3-11, hybrid progenies of ' $F_{1}$ Augusta' $\times$ BRO. (B) Lane 1, BRO; Lane 2, L. formosanum (FOR); Lanes 3-8, hybrid progenies of FOR $\times$ BRO. Arrows indicate species-specific bands.

progenies of $L . \times$ formolong $i \times \mathrm{BRO}$ had an intermediate phenotype with ovate-oblong lanceolate leaves, and flowering time ranged from late June to early July in an unheated glasshouse, whereas the progenies of L. formosanum $\times \mathrm{BRO}$ started flowering in late July and had linear-narrow leaves, which were much closer to the leaves of the maternal parent, L. formosanum. All hybrid flowers showed a yellowish cream color at the time of anthesis in the heated glasshouse, but they soon changed to white during the following 24 hours (Fig. 2). In opened field conditions, however, they possessed pale purplebrown flowers on the outer perianths similarly to L. brownii var. colchesteri. The hybrid flowers had a trumpet shape, faced down, and dark brown anthers with a fresh sweet fragrance, as does L. brownii var. colchesteri.

Hybrid progenies exhibited relatively high pollen fertility (Table 4 ). The average pollen germination rate was in the range from $7.3 \%$ to $20.4 \%$. Pollen stainability and pollen germination ability of the hybrid obtained from the cross of $L . \times$ formolongi $\times \mathrm{BRO}$ were higher than those of $L$. formosanum $\times \mathrm{BRO}$ and were much lower than those of the parental species. Capsule set was observed in self-pollinated progenies, but they bore unviable seeds with degenerated embryos.

\section{Discussion}

Isozyme analysis confirmed the hybridity of the progenies derived from interspecific crosses. The petal color changing at flowering of the hybrids suggests that the desirable trait of L. brownii var. colchesteri has been successfully introduced into the interspecific generation. To our knowledge, this is the first evidence of dominant 
Table 3. Flowering performance of hybrid plants obtained from interspecific crosses with L. brownii var. colchesteri (BRO) as the pollen parent.

\begin{tabular}{|c|c|c|c|c|c|c|c|}
\hline \multirow{3}{*}{ Female parent } & \multicolumn{6}{|c|}{ Number of plants } & \multirow{3}{*}{$\begin{array}{l}\text { Days from pollination to } \\
\text { first anthesis Ave. } \\
\text { (min-max) }\end{array}$} \\
\hline & \multirow{2}{*}{ Acclimatized } & \multirow{2}{*}{$\begin{array}{c}\text { Flowered in } 2^{\text {nd }} \\
\text { year }(\%)\end{array}$} & \multicolumn{4}{|c|}{ With multiple stalks } & \\
\hline & & & 1 & 2 & 3 & 4 & \\
\hline ' $F_{1}$ Augusta' & 115 & $43(37.4)$ & 30 & 10 & 2 & 1 & $660.6(619-683)$ \\
\hline ' $\mathrm{F}_{1}$ Julia' & 8 & $5(62.5)$ & 3 & 1 & 1 & & $662.0(628-690)$ \\
\hline 'Raizan 1' & 17 & $10(58.8)$ & 6 & 4 & & & $671.3(664-678)$ \\
\hline 'Sakigake Raizan' & 15 & $9(60.0)$ & 6 & 3 & & & $678.2(621-701)$ \\
\hline 'White Lancer' & 3 & $1(33.3)$ & 0 & 1 & & & 683.0 \\
\hline L. formosanum & 21 & $11(52.4)$ & 6 & 3 & 2 & & $695.3(665-706)$ \\
\hline Total & 179 & 79 & 51 & 22 & 5 & 1 & $675.1(619-706)$ \\
\hline
\end{tabular}
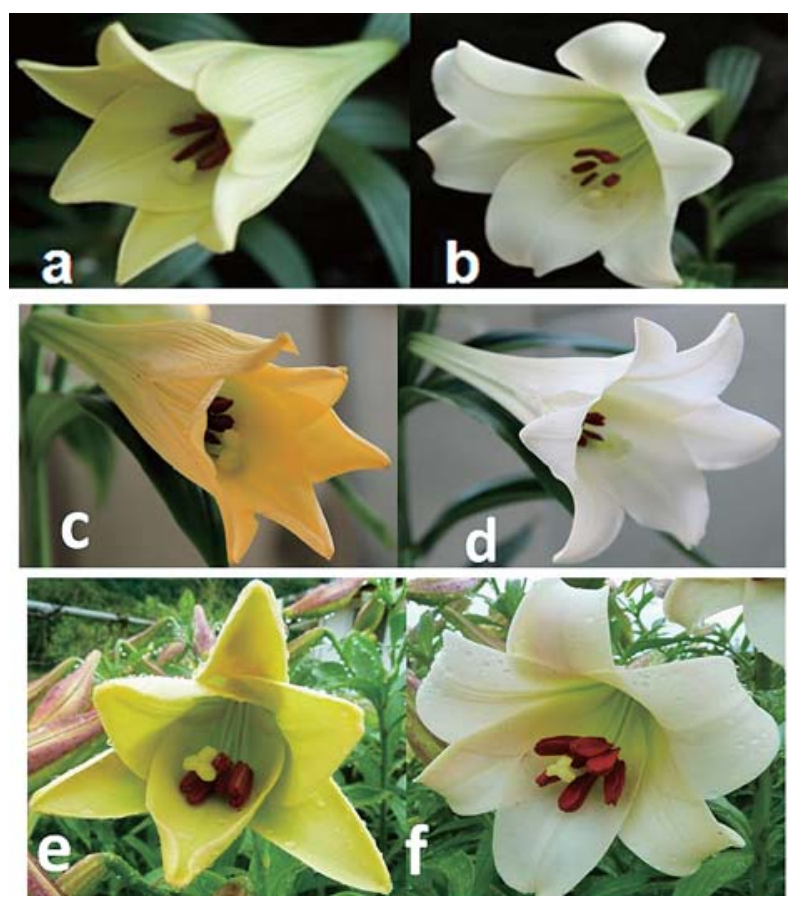

Fig. 2. Change in petal color during anthesis of L. brownii var. colchesteri $(\mathrm{e}, \mathrm{f})$ and hybrid plants from crosses of ' $\mathrm{F}_{1}$ Augusta' $\times \mathrm{BRO}(\mathrm{a}, \mathrm{b})$ and L. formosanum $\times \mathrm{BRO}(\mathrm{c}, \mathrm{d})$ at anthesis $(\mathrm{a}, \mathrm{c}$, e) and one day after anthesis (b, d, f).

inheritance of the trait of flower color change in the genus Lilium.

Among the three maternal species used in the crosses, only $L . \times$ formolongi cultivars and L.formosanum successfully resulted in hybrid seedling production, but no seedling was obtained in crosses of L. longiflorum $\times$ BRO, even when ovary slice culture was carried out. According to the phylogenetic trees constructed from internal transcribed spacer sequences of Lilium species using the maximum likelihood and neighbor-joining methods, L. brownii var. colchesteri is a little closer to L. longiflorum than to L. formosanum (Nishikawa et al., 2001), which is inconsistent with the present results of interspecific crossability; L. brownii var. colchesteri is more crossable with L.formosanum than with L. longiflorum. According to the phylogenic relationship based on AFLP (Sakazono et al., 2012), the
L. longiflorum population originated on Pitouchiao island (LPI), was the successful genotype in capsule setting in interspecific crossing with L. brownii var. colchesteri, and is the closest relative to L. formosanum in comparison with other $L$. longiflorum populations. The ability to set capsules in crosses between L. longiflorum $\times$ BRO seems consistant with the genetic relationship among L. longiflorum populations and cultivars with L. brownii var. colchesteri.

Although normal pollination brought about 20\% capsule set in these crosses, the seeds did not contain mature embryos (Table 1). It has been stated that an abnormal embryo and degenerated endosperm were the main reasons for the failure in intersectional hybridization in Lilium (Dowrick and Brandram, 1970; Van Tuyl et al., 1997). Inspection of inviable seeds from various lily interspecific crosses indicated that this failure of endosperm development occurred at varying times after fertilization and the commonest form of abnormality resulted from chromosome breakage and reunion (Dowrick and Brandram, 1970). By applying ovary slice culture after pollination, the hybrids were generated from crosses of $L . \times$ formolongi $\times \mathrm{BRO}$ and L. formosanum $\times$ $\mathrm{BRO}$, except those of $L$. longiflorum $\times \mathrm{BRO}$. This embryo rescue technique has also been successfully applied by several researchers to develop hybrids in the genus Lilium (Fernandez et al., 1996; Hayashi et al., 1986; Kanoh et al., 1988; Van Tuyl et al., 1991). The results obtained in the present research showed that interspecific hybridization between $L$. brownii var. colchesteri and its close relatives was regulated by post-fertilization restriction, which was partly overcome with the aid of ovary slice culture.

In the present study, the number of germinated ovules increased with an increase in DAP in cross combinations where ' $F_{1}$ Augusta', ' $F_{1}$ Julia', and 'White Lancer' were used as seed parents with a maximum number of germinated seedlings at $28 \mathrm{DAP}$. In contrast, germination decreased with the increase in DAP in the crosses of 'Raizan 1 ' $\times$ BRO and L. formosanum $\times$ BRO. The results suggest that the initiation time of ovary slice culture greatly influenced the production of the seedlings. These findings are similar to those obtained by Van Tuyl et al. (1991), Hayashi et al. (1986), and Kanoh et al. (1988) 
Table 4. Pollen fertility of hybrid plants obtained from interspecific crosses with L. brownii var. colchesteri (BRO) as the pollen parent.

\begin{tabular}{|c|c|c|c|c|c|c|}
\hline \multirow[b]{2}{*}{ Cross combinations } & \multirow{2}{*}{$\begin{array}{c}\text { Number of } \\
\text { examined plants }\end{array}$} & \multirow{2}{*}{$\begin{array}{c}\text { Mean pollen } \\
\text { staining rate }(\%) \\
(\text { Min-Max })^{\mathrm{z}}\end{array}$} & \multirow{2}{*}{$\begin{array}{l}\text { Mean pollen } \\
\text { germination rate } \\
(\%)(\text { Min-Max) }\end{array}$} & \multicolumn{3}{|c|}{ Number of } \\
\hline & & & & Self-pollinations & $\begin{array}{l}\text { Fruit set } \\
(\%)\end{array}$ & Mature seeds \\
\hline BRO ठ & 10 & $85.3(42.6-91.2)$ & $58.4(34.6-67.2)$ & $-\mathrm{x}$ & - & - \\
\hline $\mathrm{F}_{1}$ Augusta 우 & 5 & $77.3(35.6-89.7)$ & $61.2(38.7-71.4)$ & - & - & - \\
\hline $\mathrm{F}_{1}$ Julia 우 & 5 & $79.2(56.2-98.2)$ & $63.5(38.9-80.1)$ & - & - & - \\
\hline Raizan 1 우 & 5 & $85.3(45.2-93.2)$ & $54.8(21.9-68.2)$ & - & - & - \\
\hline Sakigake Raizan 우 & 5 & $86.5(46.8-95.6)$ & $57.7(32.4-72.3)$ & - & - & - \\
\hline White Lancer 우 & 5 & 81.7 (55.8-91.4) & $48.1(19.5-57.8)$ & - & - & - \\
\hline L. formosanum 우 & 5 & $83.7(57.8-90.2)$ & $55.6(19.2-64.3)$ & - & - & - \\
\hline ' $\mathrm{F}_{1}$ Augusta' $\times \mathrm{BRO}$ & 10 & 74.7 (52.0-99.2) & $20.4(8.6-45.4)$ & 23 & $17(73.9)$ & 0 \\
\hline ' $\mathrm{F}_{1}$ Julia' $\times$ BRO & 5 & $68.7(0-98.2)$ & $12.1(0-50.0)$ & 9 & $4(80.0)$ & 0 \\
\hline 'Raizan 1'×BRO & 10 & $55.7(24.7-84.0)$ & $16.8(0-35.6)$ & 10 & $7(70.0)$ & 0 \\
\hline 'Sakigake Raizan' × BRO & 9 & $61.7(0.8-91.6)$ & $17.9(0-58.3)$ & 11 & $6(66.7)$ & 0 \\
\hline 'White Lancer' $\times$ BRO & 1 & $60.9(4.1-81.2)$ & $10.5(0-21.8)$ & 3 & $1(33.3)$ & 0 \\
\hline L. formosanum $\times \mathrm{BRO}$ & 11 & $48.3(0-81.5)$ & $7.3(0-31.0)$ & 13 & $7(53.8)$ & 0 \\
\hline
\end{tabular}

z Pollen grains were stained in a drop of acetocarmine.

${ }^{y}$ Pollen grains were cultured on medium with $10 \mathrm{~g} \cdot \mathrm{L}^{-1}$ sucrose, $0.1 \mathrm{~g} \cdot \mathrm{L}^{-1}$ boric acid, and $1.0 \mathrm{~g} \cdot \mathrm{L}^{-1}$ agar at $25^{\circ} \mathrm{C}$ for $4 \mathrm{~h}$.

$x$ - not examined.

At least 500 pollen grains were observed in each plant.

Table 5. Growth and flower characteristics of L. brownii var. colchesteri (BRO) and its interspecific hybrids at flowering time.

\begin{tabular}{|c|c|c|c|c|c|c|c|}
\hline Cross combinations & $\begin{array}{l}\text { Number } \\
\text { of plants }\end{array}$ & Flowering time & Flower shape & $\begin{array}{c}\text { Leaf index } \\
\text { (length/width) }\end{array}$ & $\begin{array}{c}\text { Color change } \\
\text { after } \\
\text { anthesis }\end{array}$ & $\begin{array}{l}\text { Flower } \\
\text { diameter } \\
(\mathrm{cm})^{\mathrm{y}}\end{array}$ & $\begin{array}{c}\text { Flower tube } \\
\text { length } \\
(\mathrm{cm})^{\mathrm{x}}\end{array}$ \\
\hline $\mathrm{BRO}\left(\sigma^{\nearrow}\right)$ & 5 & Early June & Trumpet, face down & $5.22 \pm 0.14$ & Yes & $8.93 \pm 2.05$ & $11.89 \pm 1.94$ \\
\hline 'F $\mathrm{F}_{1}$ Augusta' ( 우 ) & 10 & July & Trumpet, face up & $4.01 \pm 0.06$ & No & $13.64 \pm 2.16$ & $14.87 \pm 2.18$ \\
\hline L. formosanum ( 우) & 10 & Late July-early August & Trumpet, face down & $27.50 \pm 0.79$ & No & $12.25 \pm 2.83$ & $16.75 \pm 1.34$ \\
\hline ' $\mathrm{F}_{1}$ Augusta' $\times \mathrm{BRO}$ & 9 & Late June-early July & Trumpet, face down & $6.93 \pm 0.33$ & Yes & $11.76 \pm 2.97$ & $13.69 \pm 4.40$ \\
\hline ' $\mathrm{F}_{1}$ Julia' $\times$ BRO & 5 & Late June-early July & Trumpet, face down & $8.74 \pm 1.0$ & Yes & $12.10 \pm 2.83$ & $14.28 \pm 3.42$ \\
\hline 'Raizan 1 '× BRO & 10 & Late June-early July & Trumpet, face down & $5.88 \pm 0.23$ & Yes & $13.27 \pm 2.64$ & $14.93 \pm 3.21$ \\
\hline 'Sakigake Raizan' × BRO & 9 & Late June-early July & Trumpet, face down & $7.59 \pm 0.37$ & Yes & $9.05 \pm 4.89$ & $12.23 \pm 1.93$ \\
\hline 'White Lancer' $\times$ BRO & 1 & Late June-early July & Trumpet, face down & $7.65 \pm 0.21$ & Yes & $13.40 \pm 2.07 *$ & $14.61 \pm 2.76^{*}$ \\
\hline L. formosanum $\times \mathrm{BRO}$ & 11 & Late July-early August & Trumpet, face down & $10.63 \pm 0.62$ & Yes & $12.53 \pm 3.12$ & $13.38 \pm 2.09$ \\
\hline
\end{tabular}

${ }^{\mathrm{z}} \operatorname{Mean} \pm \operatorname{SE}(\mathrm{n}=20)$.

$y, x$ Mean $\pm \operatorname{SE}(n=5, * n=3)$.

who illustrated that ovary slice culture can enhance the chance of success in developing new hybrids between distantly related lily species if the appropriate time for culture was 7, 20, and 40 DAP, respectively. From this, we suggest that the most appropriated time for starting ovary slice culture in crosses between L. brownii var. colchesteri and these Longiflorum lilies is 28 DAP for ' $F_{1}$ Augusta', ' $F_{1}$ Julia', and 'White Lancer', 14 DAP for 'Raizan 1', and 7 DAP for L. formosanum.

Lilium formosanum is well known for its "precocious flowering" and "multiple stalks", i.e., it can reach anthesis within 12 months from seed sowing and more than two stalks emerge a year (Hiramatsu et al., 2002; McRae, 1998; Wilson, 1925). In this study, about 22-24 months after pollination, $79(44.1 \%)$ of 179 acclimatized plants flowered, of which 28 (35.4\%) plants had two or more stalks. In fact, these hybrids required about one year after bulblet acclimatization for the first flower to emerge. It seems that the "precocious flowering" and "multiple stalks" traits are inherited dominantly by the hybrids. This observation is consistent with the results reported by Saruwatari et al. (2008) in crosses of L. formosanum $\times$ Asiatic hybrids. Therefore, L. brownii var. colchesteri, which is difficult to maintain naturally in the field under our conditions, can be replaced by its hybrid progenies which show vigorous growth, early flowering, and the most important trait, changing petal color.

Self-pollination of the hybrids produced no mature seeds although pollen fertility was relatively high. It has been reported that recurrent or introgressive backcrossing is one of the most effective methods to restore hybrid fertility (Haghighi and Ascher, 1988). Alternatively, amphidiploid induction by chromosome doubling or application of functional $2 \mathrm{n}$ pollen was used to restore fertility in many interspecific hybrid lilies (Asano, 1982; 
Barba-Gonzalez et al., 2005; Van Tuyl et al., 1990, 1997). It is therefore relevant that breeding new interspecific cultivars is feasible by producing backcross and chromosome doubling progenies to recover seed production ability and to introduce the attractive ornamental characteristics of $L$. brownii var. colchesteri through stigmatic pollination followed by the embryo rescue technique.

In brief, interspecific hybrid progenies were successfully produced by interspecific crosses between L. brownii var. colchesteri and its close relatives, $L . \times$ formolongi and L.formosanum using the ovary slice culture technique. These progenies might develop into new lily cultivars with flower color change and sexual propagation ability if gametic fertility is recovered after the second generation.

\section{Literature Cited}

Asano, Y. 1982. Overcoming interspecific hybrid sterility in Lilium. J. Japan. Soc. Hort. Sci. 51: 75-81.

Barba-Gonzalez, R., K. B. Lim, M. S. Ramanna and J. M. van Tuyl. 2005. Use of $2 n$ gametes for inducing intergenomic recombination in lily hybrids. Acta Hort. 673: 161-166.

Beattie, D. J. and J. W. White. 1993. Lilium - hybrids and species. p. 423-545. In: A. De Hertogh and M. Le Nard (eds.). The physiology of flower bulbs. Elsevier Science Publish, Amsterdam.

Benschop, M., R. Kamenetsky, M. Le Nard, H. Okubo and A. De Hertogh. 2010. The global flower bulb industry: production, utilization, research. Hort. Res. 36: 1-115.

Dowrick, G. J. and S. N. Brandram. 1970. Abnormalities of endosperm development in Lilium hybrids. Euphytica 19: 433-442.

Fernandez, A. M., T. Nakazaki and T. Tanisaka. 1996. Development of diploid and triploid interspecific hybrids between Lilium longiflorum and L. concolor by ovary slice culture. Plant Breed. 115: 167-171.

Fukai, S. and K. Tsuji. 2004. Interspecific hybrids between Lilium $\times$ formolongi and some Asian Trumpet species. J. Japan. Soc. Hort. Sci. 73: 447-452.

Haghighi, K. R. and P. D. Ascher. 1988. Fertile, intermediate hybrids between Phaseolus vulgaris and P. acutifolius from congruity backcrossing. Sex. Plant Reprod. 1: 51-58.

Hayashi, M., K. Kanoh, Y. Serizawa and E. Yoon. 1986. Ovary slice culture of Lilium formosanum Wallace. Japan. J. Breed. 36: 304-308.

Hiramatsu, M., K. Ii, H. Okubo, K-L. Huang and C-W. Huang. 2001. Biogeography and origin of Lilium logiflorum and L.formosanum (Liliaceae) endemic to the Ryukyu Archipelago and Taiwan as determined by allozyme diversity. Am. J. Bot. 88: 1230-1239.

Hiramatsu, M., H. Okubo, K. Yoshimura, K-L. Huang and C-W. Huang. 2002. Biogeography and origin of Lilium longiflorum and L.formosanum II, Intra- and Interspecific variation in stem leaf morphology, flowering rate and individual net production during the first year seedling growth. Acta Hort. 570: 331-334.

Jefferson-Brown, M. and H. Howland. 1995. The gardener's guide to growing lilies. Timber Press, Portland.

Kanoh, K., M. Hayashi, Y. Serizawa and T. Konishi. 1988. Production of interspecific hybrids between Lilium longiflorum and L. × elegance by ovary slice culture. Japan. J. Breed. 38: 278-282.

Leslie, A. C. 1982 . The international lily register, $3^{\text {rd }}$ edn. The Royal Horticultural Society, London.

Löffler, H. J. M., H. Meijer, T. P. Straathof and J. M. Van Tuyl. 1996. Segregation of fusarium resistance in an interspecific cross between Lilium longiflorum and Lilium dauricum. Acta Hort. 414: 203-208.

McRae, E. A. 1998. Lilies. A guide for growers and collectors. Timber Press, Portland.

Murashige, T. and F. Skoog. 1962. A revised medium for rapid growth and bioassays with tobacco tissue culture. Physiol. Plant. 15: 473-497.

Niimi, Y. and Y. Shiokawa. 1992. A study on the storage of Lilium pollen. J. Japan. Soc. Hort. Sci. 61: 399-403.

Nishikawa, T., K. Okazaki, K. Arakawa and T. Nagamine. 2001. Phylogenetic analysis of section Sinomartagon in genus Lilium using sequences of the internal transcribed spacer region in nuclear ribosomal DNA. Breed. Sci. 51: 39-46.

Okubo, H. 2006. History of Lilium brownii var. colchesteri in Japan. Sci. Bull. Fac. Agr. Kyushu Univ. 61: 145-163 (In Japanese with English summary).

Sakazono, S., M. Hiramatsu, K-L. Huang, C-L. Huang and H. Okubo. 2012. Phylogenetic relationship between degree of self-incompatibility and floral traits in Lilium longiflorum Thunb. (Liliaceae) J. Japan. Soc. Hort. Sci. 81: 80-90.

Saruwatari, H., Y. S. Nakano, K. Nakano, M. Hiramatsu, Y. Ozaki and H. Okubo. 2008. Interspecific lily hybrids with the ability to flower precociously and to produce multiple flower stalks from Lilium formosanum. J. Japan. Soc. Hort. Sci. 77: 312317.

Sashida, Y., S. Kubo, Y. Mimaki, T. Nikaido and T. Ohmoto. 1992. Steroidal saponins from Smilax riparia and S.china. Phytochemistry 31: 2439-2443.

Shimizu, M. 1971. Lilies of Japan (In Japanese). Seibundo Shinkosha, Tokyo.

Van Creij, M. G. M., D. M. F. J. Kerckhoffs and J. M. Van Tuyl. 1998. Application of four pollination techniques and of hormone treatments for bypassing interspecific crossing barriers in Lilium L. Acta Hort. 508: 267-276.

Van Creij, M. G. M., L. W. D. Van Raamsdonk and J. M. Van Tuyl. 1993. Wide interspecific hybridization of Lilium: Preliminary results of the application of pollination and embryo rescue methods. Lily Yearbook NALS 43: 28-37.

Van Tuyl, J. M. 1980. Lily breeding research at IVT in Wageningen. Lily Yearbook NALS 33: 75-82.

Van Tuyl, J. M., H. S. Chi, B. C. M. Van Kronenburg and B. Meijer. 1997. Interspecific lily hybrids: a promise for the future. Acta Hort. 430: 539-544.

Van Tuyl, J. M., J. Franken, R. C. Jongerius, C. A. M. Lock and T. A. M. Kwakkenbos. 1986. Interspecific hybridization in Lilium. Acta Hort. 177: 591-595.

Van Tuyl, J. M., M. P. Van Dien, M. G. M. Van Creij, T. C. M. Van Kleinwee, J. Franken and R. J. Bino. 1991. Application of in vitro pollination, ovary culture, ovule culture and embryo rescue for overcoming incongruity barriers in interspecific Lilium crosses. Plant Sci. 74: 115-126.

Van Tuyl, J. M., H. M. C. Van Holsteijn and A. A. M. Kwakkenbos. 1990. Research on polyploidy in interspecific hybridization of lily. Acta Hort. 266: 323-330.

Wilson, E. H. 1925. The lilies of Easten Asia. Dulau and Company, London.

Yang, S. S. 2000. Lilium. p. 49-52. In: T. C. Huang (ed.). Flora of Taiwan. National Taiwan University, Taipei. 